\section{Visual masking by light offset}

\author{
R. JAMES HOLZWORTH and MICHAEL E. DOHERTY \\ Bowling Green State University, Bowling Green, Ohio 43402
}

Two experiments are reported which investigated whether or not the offset of light can serve as a backward masking stimulus (MS). In both studies, human Os made identification responses to graphemes (TS) presented tachistoscopically on a lighted field. Simultaneously with or at short intervals after TS offset, the lighted background field was shut off. The termination of the background field served as the MS. The results indicated a reliable masking effect due to light offset; this effect occurred for TS-MS intervals of $60 \mathrm{msec}$ or less. These results were interpreted as being due to the "off" response in the visual system.

Visual masking refers to the situation in which the perceptibility of a visual stimulus (the test stimulus, TS) is reduced by the presentation of another visual stimulus (the masking stimulus, MS) in close temporal contiguity (Kahneman, 1968). The TS may be either a patch of light or a form. Classes of stimuli which have functioned as MS have included light, regular patterns, or random patterns. These may either precede or follow TS, and the two may or may not spatially overlap. A number of studies investigating the phenomenon of visual masking have claimed the masking function to result from the "on" response to the masking stimulus (Boynton, 1958, 1961; Boynton \& Kandel, 1957; Boynton \& Siegfried, 1962; Onley \& Boynton, 1962; Baker, 1955,1963 ). If masking, measured behaviorally, is related to the "on" response measured electrophysiologically, then recent reports of two electrophysiological investigations (Nakayama, 1968; Schiller, 1968) would lead one to suspect that masking might also occur as a function of the "off" response. That is, at a behavioral level, visual masking may well occur when light offset is employed as the MS.

Schiller (1968), in single unit analysis in the cat lateral geniculate nucleus (LGN), obtained unit responses which bear correspondence with masking due to the "off" response. He examined discharge characteristics of "off"-center cells (from Layer A of the LGN) to paired superimposed stimuli. Two brief flashes were presented within a short time interval. As the interstimulus interval was decreased, the "off" burst to the first stimulus was inhibited more and more, until it was no longer present. The inhibition of the "off" burst to the first flash was complete by 100 msec.

Nakayama (1968), also investigating single-unit responses in the cat visual system, obtained a backward masking effect in "off"-center cells in the optic nerve. A short "off" discharge to a receptive field center was followed by an "off" discharge to the receptive field surround. The effect of the second "off" discharge was studied as a function of the interstimulus interval. The investigation demonstrated that a darkening of the receptive field surround could inhibit a response elicited by a darkening of the receptive field center. Further, the amount of inhibition increased as the interstimulus interval was shortened from 30 to 0 msec (Nakayama, 1968).

In addition, recent investigations by Eriksen and Collins (1967, 1968; Schurman, Eriksen, \& Rohrbaugh, 1968) suggest that "discontinuity detectors" may be responsible for the breaking up of incoming stimulation. They suggest such a role for the "off" response at the level of the retina. They further suggest that the monotonic negatively accelerated masking functions might be viewed in part as threshold functions for discontinuity detection (Eriksen, 1966; Eriksen \& Collins, 1965).

In light of the recent electrophysiological evidence and of the suggestion that "discontinuity detectors" may disrupt incoming stimulation, it appears that more research is needed to investigate the role of the "off" response in visual perception. The purpose of this study was to determine at the behavioral level if there was any masking effect due to light offeet and thus, inferentially, a masking effect due to the "off" response in the visual system.

\section{EXPERIMENT 1}

\section{Method}

Subjects. Four Bowling Green State University undergraduate students, two males and two females, served as paid Ss. They were naive as to the purpose of the study. All had normal, or corrected to normal, vision. Every S had three pretraining sessions. Ss 1,2 , and 3 each served in 10 experimental sessions, $S 4$ in 13. Each pretraining and experimental session lasted approximately $50 \mathrm{~min}$.

Design. A repeated measures design was chosen in which each $\mathbf{S}$ was tested under each of nine experimental conditions and a control condition during each session. Each condition occurred in counterbalanced order in blocks of 18 trials. The independent variable was the time interval between the onset of the TS and the offeet of the lighted adapting field (TS-MS interval). The offset of the adapting field was labeled the MS; therefore, the independent variable was the TS-MS interval. The dependent variables were the percentage of correct identifications of TS letters (A, $\mathrm{T}$, or $\mathrm{U}$ ) and the response indicating $S$ 's degree of confidence in identifying each letter.

Apparatus and stimuli. A three-field Scientific Prototype Model GB autotachistoscope was employed. Field 1 served as the stimulus field. Field 3 served as the adapting field containing a fixation point. Field 2 remained off at all times, but its timer was used. The stimulus forms consisted of the capital letters $A, T$, and $U$ from Para-Tipe Sheet No. 11185 (8-pt News Gothic Condensed). These letters were chosen because research by Eriksen (1966) had shown them to be approximately equally discriminable and equally confusable with one another when presented for short durations. The letters were photographed using high-contrast film, and the negatives were mounted into $35 \cdot \mathrm{mm}$ slide mounts. The back-lighted slides produced white letters upon the white background provided by Field 3. Each stimulus subtended a visual angle of 0.31 deg. The TS and background luminances, measured by a Pritchard photometer with the beam-splitter head of the tachistoscope removed, were 7.5 and $20.0 \mathrm{~mL}$, respectively. The background field had a pin-point black fixation point appearing $.2 \mathrm{deg}$ below where the TS was to appear. One TS appeared directly above the fixation point on every trial.

Procedure. The experiment was conducted in a well-lighted room in order to maintain S's light adaptation. All viewing was monocular with S's preferred eye. Three pretraining sessions were conducted to familiarize each $S$ with the apparatus and procedure and to overcome an eariy practice effect before beginning the actual experiment. During these sessions, an exposure duration for TS was chosen for each $\mathbf{S}$ which resulted in a forced-choice identification accuracy of between $50 \%$ and $70 \%$ under the condition of constant background luminance; that is, no MS followed the TS (control condition). The exposure duration selected for each $\mathbf{S}$ was used throughout the entire experiment. The Ss were instructed 


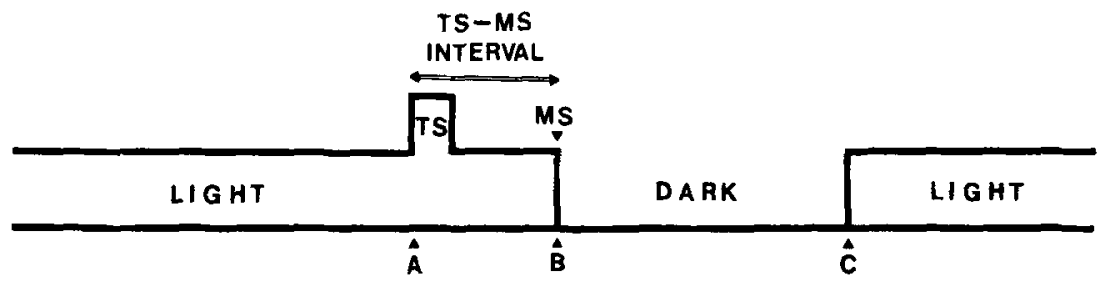

Fig. 1. Summary of the temporal aspects of the experimental procedure. Field 3 is lighted, containing only a fixation point. The $S$ fixes his eye to the eyepiece and, at $A$, depresses the handswitch which causes Field 1 , with the TS, to be superimpoged on the background field for a brief duration. Field 3 remains on briefly, then terminates at $B$, making the visual field black. This signals $S$ to respond. The Field 2 timer controlling the dark interval times out at $C$, the slide changes automatically, and Field 3 comes back on. The $S$ is then free to begin the cycle over again.

that each letter would be shown randomly but equally often. The exposure durations selected for Ss 1 , 2,3 , and 4 were $27.5,15.0,14.0$, and 14.0 msec, respectively.

During the experiment, each $\mathbf{S}$ was allowed 18 practice trials at the beginning of each session. The $\mathbf{S}$ was instructed to fixate on the fixation point, after having placed his preferred eye firmly into an eyecup surrounding the eyepiece of the tachistoscope. This, along with an eyepatch over the other eye, was used in order to eliminate extraneous light from entering $S$ 's eye during an observation. When the fixation point appeared "clear and sharp," $S$ initiated the TS by squeezing a handswitch. The TS appeared immediately upon the lighted Field 3 for the duration selected for each $\mathbf{S}$ during pretraining. Field 3 remained on for varying time intervals, depending upon the particular experimental condition. The termination of Field 3 served as the MS. The S was instructed to look into the eyepiece until the stimulus field became totally black. Nine TS-MS intervals were investigated: concurrent, $20,40,60,80,100,150$, 200 , and 300 msec. The concurrent condition was one in which TS offset and Field 3 offset were simultaneous, making the concurrent condition slightly different for each $\mathrm{S}$. For $\mathrm{S} 1$, the 20 -msec interval was replaced by a 35-msec TS-MS interval. A 10th condition (no MS) served as a control condition in which there was no Field 3 offset following TS. That is, a TS simply appeared with no darkness following. The dark period lasted from 4.70 to $4.98 \mathrm{sec}$, depending on the experimental condition and the exposure duration of the TS. This period was regulated by the Field 2 timer. The return of the adapting field was accompanied by a new TS slide. The $S$ was instructed not to look into the tachistoscope until the adapting field reappeared. This limited $S$ to an interobservation interval of at least $5 \mathrm{sec}$. Figure 1 contains a summary of the temporal aspects of the experiment.

Within an experimental session, Ss were required to make 18 identifications at each of the nine TS-MS intervals and the control condition. Thus, in each session, a total of 180 identifications were made in blocks of 18 trials following the practice trials. Each condition occurred equally often and in counterbalanced order. There were frequent rest pauses during each session. Data collected during the first five experimental sessions from $\$ 4$ were eliminated from consideration, since during the fifth session $E$ noted that she was not following instructions. $\$ 4$ had formed a habit of looking into the eyepiece before Field 3 reappeared, thus creating a possible confounding with a forward masking effect due to the onset of the background field.

The S's responses were made on a response panel located at his side. In addition to the identifications, confidence judgments were required on each trial. Each $S$ indicated whether he was "very sure," "somewhat sure," or "just guessing" on each trial. The Ss responded by pressing one of nine buttons on the columns. Each column represented a letter ( $A, T$, and $U$ ), and each row represented a degree of confidence in identification. Each $S$ received immediate feedback on each trial by a light in the appropriate column. The $\mathrm{E}$ had a display panel, hidden from $S$, which informed him of S's response.

Following the experiment, each $S$ underwent a postexperimental interview, after which he was told the purpose of the study.

\section{Results}

Percentages of correct identifications for each condition were plotted for each $S$ (see Fig. 2). Confidence judgment data were also analyzed, but the results were in agreement with the identification data, response panel arranged in three and only the latter will be reported. There was a markedly lower identification accuracy at very short intervals for Ss 1 and 2. S 1 showed the greatest decrement of the four Ss, with a sharp decrease in identification accuracy at very brief TS-MS interval conditions. S 2 showed a substantial and S 3 a slight decrement in identification accuracy at the very shortest TS-MS intervals. S 4 showed virtually no decrement over decreasing TS-MS intervals, showing instead a slight tendency in the opposite direction at very short intervals.

The data indicated the possibility of a backward masking effect due to the offset of a lighted field at very short TS-MS intervals, but not conclusively so.

The results indicated that the TS exposure durations selected for Ss 3 and 4 had resulted in such low levels of identification accuracy that relatively little opportunity remained for a performance decrement. Since three TS letters were used, $S$ could be expected to perform at a $33 \%$ accuracy level by chance alone. Since the selected TS exposure durations for Ss 3 and 4 resulted in accuracy levels in the control condition of $52 \%$ and $50 \%$, respectively, there was a relatively small range in which to show a decrement. A second experiment was conducted.

\section{EXPERIMENT 2}

\section{Method}

Subjects. Ten Bowling Green State University undergraduate students, four males and six females, served as volunteer Ss. All were enrolled in the introductory psychology course and were fulfilling part of a research participation requirement. They were naive as to the purpose of the experiment. IAll Ss had normal, or corrected to normal, vision. Ss 6 and 9 wore contact lenses. Each $S$ served in one pretraining session and one experimental session, each lasting approximately $50 \mathrm{~min}$.

Design. A randomized block design with repeated measures was used (Kirk, 1968, p. 131). Each S made 45 identification responses under each of four experimental conditions. The independent variable was the TS-MS interval. The dependent variables were the percentages of correct identifications of TS letters and responses indicating $S$ 's degree of confidence in identifications. Again, only the former are reported.

Apparatus and stimuli. The apparatus and stimuli used in this experiment were identical to those used in the initial experiment.

Procedure. The procedure followed was the same as the above except for the following changes. Each S 


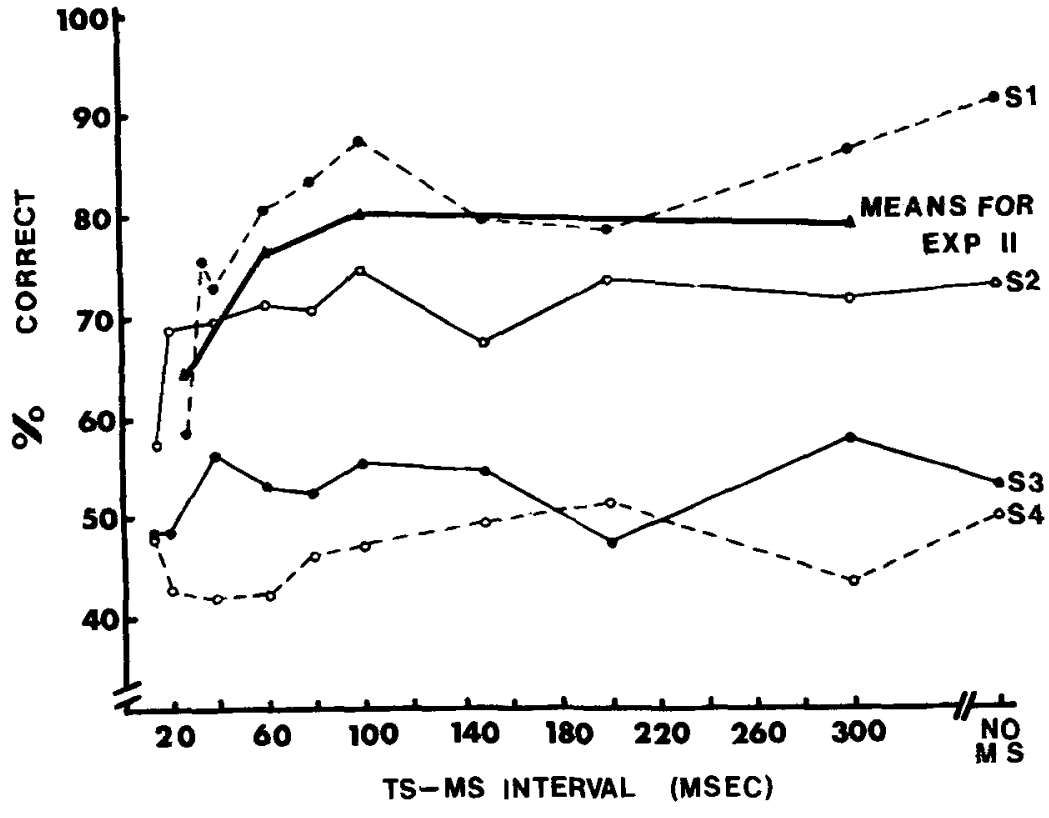

Fig. 2. The backward masking functions for individual Ss in Experiment 1 and for the means of the $10 \mathrm{Ss}$ in Experiment 2. participated in a session on 2 successive days. The first session was a pretraining period during which each $\mathrm{S}$ became introduced to the apparatus and procedure. It also enabled Ss to overcome an early practice effect. During the pretraining session, a TS exposure duration was selected for each $S$ which would result in a forced-choice identification accuracy of between $70 \%$ and $90 \%$, given the 300-msec TS-MS interval condition.

During the experimental session, each $S$ was given 18 practice trials at the 300-msec TS-MS interval before beginning the actual experiment. If the results of the practice trials appeared consistent with those obtained the preceding day under the same condition, the experiment was begun. If the practice results differed considerably from those obtained during the pretraining session, a slightly different TS exposure duration was selected and maintained throughout the experimental session.

Four TS-MS intervals were investigated: concurrent, 60,100 , and $300 \mathrm{msec}$. There were 20 blocks of trials within the experimental session. Each block consisted of nine trials. Each experimental condition was replicated five times in counterbalanced order. Thus, ihere were 45 trials at each of the four conditions. This resulted in a total of 180 experimental trials per $S$ during the experimental session.

\section{Results}

Table 1 shows the percentage of correct identifications at each of the four conditions for each $\mathrm{S}$. The results clearly indicate the occurrence of a backward masking effect ( $F=9.42$, $\mathrm{df}=3,27, \mathrm{p}<.001$ ). All 10 Ss showed a decrement in identification accuracy from the $60-\mathrm{msec}$ TS-MS interval condition to the concurrent condition. Tukey's HSD test indicated a significant difference between the concurrent and all other conditions $(\mathrm{p}<.01)$ but no significant differences among the 60-, 100-, and $300-\mathrm{msec}$ conditions. Thus, masking occurred within the first $60 \mathrm{msec}$ after TS onset. There was no evidence of an effect at TS-MS intervals greater than 60 msec.

\section{DISCUSSION}

The backward masking effect obtained with the offset of a lighted field is probably due to the neural "off" response known to occur with light offset.
The results of the present study are consistent with the electrophysiological investigation of Nakayama (1968) referred to above. Both obtained backward masking due to the "off" response at very short delay intervals between TS and MS. He found inhibition of the "off" response to a receptive field center due to the "of $f$ " response to the receptive field surround, providing MS occurred within $30 \mathrm{msec}$ of TS of fset. That time course is similar to the one found in the present study, for his interval does not include the duration of the TS. If one were to transform the TS-MS interval in the present study into the type considered by Nakayama, one would find a masking effect within $30 \mathrm{msec}$ of TS offset. Nakayama suggests that backward visual masking occurs in the retina and is due to differential excitation and transmission time for the TS and MS. A difference in transmission time increases the portion of the neural response to TS which is vulnerable to interference by the MS. Further, he maintains that the principle mechanism is that of lateral inhibition, found in the retina, acting within the organization of a cell's receptive field. Lateral inhibition is suggested since both homogeneous and annular blanking flashes have a similar power to inhibit a discharge triggered by an earlier TS. Although he does not rule out higher centers as possible sites for the inhibitory effect, Nakayama suggests that the amacrine cells of the inner nuclear layer of the retina may be responsible for the inhibition observed in optic nerve axons as well as the inhibition inferred from psychophysical studies of masking. The laterally conducting amacrine cells connect neighboring bipolar cells in a two-way fashion. This enables excitation from a MS in one receptor-bipolar pathway to interact simultaneously with some of the excitation from an earlier TS traveling through an adjacent receptor-bipolar pathway. Nakayama cites some
Table 1

Exposure Durations and Percentage of Correct Identifications in Each Condition for Each $S$ in Experiment 2

\begin{tabular}{|c|c|c|c|c|c|}
\hline \multirow[b]{2}{*}{ Ss } & \multirow{2}{*}{$\begin{array}{l}\text { Exposure } \\
\text { Duration } \\
\text { in Msec }\end{array}$} & \multicolumn{4}{|c|}{ TS-MS Interval } \\
\hline & & Concurrent & $60 \mathrm{Msec}$ & $100 \mathrm{Msec}$ & 300 Msec \\
\hline 1 & 20 & 82 & 84 & 91 & 87 \\
\hline 2 & 25 & 69 & 87 & 91 & 87 \\
\hline 3 & 25 & 73 & 76 & 78 & 87 \\
\hline 4 & 35 & 76 & 82 & 82 & 78 \\
\hline 5 & 20 & 56 & 71 & 78 & 60 \\
\hline 6 & 40 & 42 & 44 & 42 & 51 \\
\hline 7 & 20 & 64 & 84 & 96 & 89 \\
\hline 8 & 25 & 73 & 78 & 80 & 93 \\
\hline 9 & 25 & 64 & 73 & 73 & 60 \\
\hline 10 & 20 & 53 & 76 & 84 & 78 \\
\hline Mean & & 65 & 76 & 80 & 77 \\
\hline
\end{tabular}


electron microscope work which indicates that the amacrine cells mediate "surround" effects observed in relation to a receptive field, and that the bipolar ganglion cell pathway serves the center. In addition, the amacrine cells have the morphological characteristics of nerve cells having two-way interactions between bipolar cells. Nakayama further contends that the above scheme is responsible for mediating backward masking effects utilizing overlapping or adjacent MS. Finally, he cites evidence that there is a response latency difference between TS and MS. The latency of a neural response is inversely related to the absolute intensity of the stimulus. Therefore, a stronger MS may "catch up" with a weaker TS. It seems that a system such as Nakayama proposes could account for the masking by offset found in the present study.

Results of the present study are also consistent with the electrophysiological study of Schiller (1968). Investigating discharge characteristics of "off"-center cells in the cat's lateral geniculate nucleus, Schiller observed the suppression of the "off" response to a brief TS flash due to the "off" response to a brief superimposed MS flash. He found masking at longer intervals than the present study, however. The backward masking effect became greater as $\mathrm{E}$ went down from 500 to $100 \mathrm{msec}$, with complete inhibition by 100 msec.

Uttal (1970) has challenged lateral inhibitory interaction as the basic foundation of sequential masking effects. He maintains that central cognitive mechanisms are involved in the masking effects found with continuous visual forms as well as with dot patterns. Uttal cites the electrophysiological investigation of Schiller (1968) as evidence against lateral inhibition as an explanation of masking in general. Such criticism (of lateral inhibition) must be made with caution, however, for, although Schiller did not obtain results corresponding to the behaviorally obtained U-shaped masking function with nonoverlapping stimuli, he did obtain inhibition occurring in an increasing monotonic function as the interstimulus interval was shortened. Thus, masking occurred, but not in the fashion obtained in behavioral studies using metacontrast paradigms. Nakayama (1968) obtained results similar to Schiller's (1968) in that a monotonic masking function was reported with nonoverlapping visual stimuli. The fact that U-shaped functions were not obtained is no reason to reject the mechanism of lateral inhibition as a contributing factor in visual masking. Schiller (1968) and Nakayama (1968) suggest that metacontrast is a complex phenomenon, probably depending on central effects in the nervous system. They do not, however, reject lateral inhibition as a contributing mechanism. While the present study is tentatively interpreted in terms of lateral inhibition, there have obviously been no operations employed to rule out central factors.

Eriksen (1966), theorizing specifically about masking by a light flash, proposed that the luminances of the TS and MS summate within a critical interval, resulting in a reduction in figure-ground contrast. In the present study, for short TS-MS intervals there was less illumination following the TS. Generalizing the temporal luminance summation theory to the present study, there should have been a facilitation in the short delay conditions due to a greater degree of figure-ground contrast.

Kahneman (1965) suggested that masking might be a result of the prevention or retardation of bounding contours. This hypothesis also fails to account for masking in the present study since contours should, it seems, be more pronounced when there is an early onset of darkness following a lighted TS. Such did not appear to be the case in the present study. It must be mentioned that the theories of Kahneman (1965) and Eriksen (1966) were proposed to deal with masking by light (as opposed to darkness).

In postexperimental interviews, and occasionally during an experimental session, virtually all Ss reported seeing what Es interpreted as figural afterimages of the TS upon the darkened field on some trials. They indicated that it was the afterimage alone which enabled them to identify the TS. A tally of the number of times they appeared, or during which conditions they predominated, was never made, but it seemed clear that they were relatively rare. Shorter TS-MS intervals might have led to the appearance of more afterimages due to the greater amount of darkness immediately following TS. An interesting question arises when one considers the possibility of competition between the afterimages and the "off" response. It is possible that the afterimage was reducing the masking effect due to the "off" response. The question of the relation between masking by light offset and afterimages will be investigated in future studies.

Given the conditions of the present study, there seems to be a highly reliable phenomenon of masking by darkness, which is of potentially considerable importance for a wide variety of theories of visual system functioning.

\section{REFERENCES}

BAKER, H. D. Some direct comparisons between light and dark adaptation. Journal of the Optical Society of America, 1955, 45, 839-844.

BAKER, H. D. Initial stages of light a daptation. Journal of the Optical Society of America, 1963, 53, 98-103.

BOYNTON, $R$. M. On-responses in the human visual system as inferred from psychophysical studies of rapid adaptation. Archives of Ophthalmology, $1958,60,800-810$

BOYNTON, R. M. Some temporal factors in vision. In W. A. Rosenblith (Ed.), Sensory communication. New York: Wiley, 1961. Pp. $739-756$.

BOYNTON, R. M., \& KANDEL, G. On responses in the human visual system as a function of adaptation level. Journal of the Optical Society of America, 1957, 47. 275-286.

BOYNTON, R. M., \& SIEGFRIED, J. B. Psychophysical estimates of on-responses to brief light flashes. Journal of the Optical Society of America, 1962, 52, $720-721$.

ERIKSEN, C. W. Temporal luminance summation effects in backward and forward masking. Perception \& Psychophysics, 1966, 1, 87-92.

ERIKSEN, C. W., \& COLLINS, J. F. A reinterpretation of one form of backward and forward masking in visual perception. Journal of Experimental Psychology, 1965, 70, 343-351.

ERIKSEN, C. W., \& COLLINS, J. F. Some temporal characteristics of visual pattem perception. Journal of Experimental Psy chology, 1967, 74, 476-484.

ERIKSEN, C. W., \& COLLINS, J. F. Sensory traces versus the psychological moment in the temporal organization of form. Journal of Experimental Psychology, 1968, 77, 376-382.

KAHNEMAN, D. Method, findings, and theory in studies of visual masking. Psychological Bulletin, 1968, 70, 404-425.

KIRK, R. E. Experimental design: Procedures for the behavioral sciences. Belmont, Calif: Brooks/Cole, 1968.

NAKAY AMA, $K$. An analysis of visual masking in terms of unit responses in the optic nerve and lateral geniculate body of the cat. Doctoral dissertation, University of California, Los Angeles, 1968.

ONLEY, J. W., \& BOYNTON, R. M. Visual responses to equally bright stimuli of unequal luminance. Journal of the Optical Society of America, 1962, 52, 934-940.

SCHILLER, P. H. Single unit analysis of backward visual masking and metacontrast in the cat lateral geniculate nucleus. Vision Research, 1968, 8, 855-866.

SCHURMAN, D, L. ERIKSEN, C. W., \& ROHRBAUGH, J. Masking phenomena and time intensity reciprocity for form. Journal of Experimental Psychology, $1968,78,310-317$

UTTAL, W. On the physiological basis of masking with dotted visual noise. Perception \& Psychophysics, 1970. 7, 321-327.

(Accepted for publication April 2, 1971.) 